\title{
PENGARUH UKURAN BENIH ASAL KALIMANTAN BARAT TERHADAP PERTUMBUHAN BIBIT Shorea leprosula DI PERSEMAIAN
}

(Effect of Seed Size From West Kalimantan on Seed Growth of Shorea leprosula in Nursery)

Oleh/By :

\section{Rayan dan/and Deddy Dwi Nur Cahyono}

\author{
Balai Besar Penelitian Dipterokarpa
}

\begin{abstract}
Good quality of seeds, sufficient quantities and on time treatment can determine the success of planting. This research was conducted to know the effect of seed size from West Kalimantan on seed growth of Shorea leprosula in the nursery of Dipterocarp Research Center Samarinda. Total samples were 6 provenans from Gunung Bunga, West Kalimantan. The method used was Completely Randomized Design with seed size as the treatment and 3 replicates. From observation of the seedlings the average germination was $64.22 \% \mathrm{~cm}$ for small seeds, $77 \%$ for a medium-sized seed sand $83.56 \%$ for large seeds. Average height of $26.24 \mathrm{~cm}$ for small seeds, $28.13 \mathrm{~cm}$ for a mediumsized and $34.18 \mathrm{~cm}$ for large sized. Mean while,the average diameter to small-sized grain sof $0.26 \mathrm{~cm}$, the average grain diameter to $0.28 \mathrm{~cm}$ medium-sized and large sized grainsis $0.31 \mathrm{~cm}$. Based on the analysis it was found that the largest seeds has larger percentage of germination, higher growth and larger seedling diameter than the smaller seeds. Statistically the germination percentage, the height and diameter growth were significantly different.
\end{abstract}

Keyword : seed size, seed growth, Shorea leprosula

\begin{abstract}
ABSTRAK
Bibit berkualitas baik, jumlah yang cukup dan tepat waktu merupakan faktor yang dapat menentukan keberhasilan penanaman. Penelitian ini bertujuan untuk mengetahui pengaruh ukuran benih terhadap pertumbuhan bibit $S$. leprosula di persemaian Balai Besar Penelitian Dipterokarpa Samarinda. Benih diperoleh dari populasi hutan alam Gunung Bunga Kalimantan Barat dari 6 pohon induk. Penelitian ini menggunakan Rancangan Acak Lengkap dengan perlakuan ukuran benih. Setiap pohon induk terdiri dari tiga perlakuan, diulang tiga kali dan masing-masing ulangan terdiri dari 50 benih. Dari pengamatan diperoleh hasil rata-rata daya kecambah sebesar $64,22 \%$ untuk benih berukuran kecil, 77\% untuk ukuran sedang dan 83,56\% ukuran besar. Rata-rata tinggi sebesar $26,24 \mathrm{~cm}$ untuk benih berukuran kecil $28,13 \mathrm{~cm}$ ukuran sedang dan 34,18 cm ukuran besar. Sementara itu rata-rata diameter untuk benih berukuran kecil sebesar $0,26 \mathrm{~cm}$, ukuran sedang sebesar 0,28 cm dan benih berukuran besar sebesar $0,31 \mathrm{~cm}$. Benih yang berukuran lebih besar
\end{abstract}


menghasilkan daya kecambah, pertumbuhan tinggi dan diameter bibit lebih besar dibandingkan dengan biji yang berukuran lebih kecil. Setelah dianalisis secara statistik parameter daya kecambah, pertumbuhan tinggi dan diameter menunjukkan hasil berbeda nyata.

\section{Kata kunci : ukuran benih, pertumbuhan bibit, Shorea leprosula}

\section{PENDAHULUAN}

Potensi hutan Indonesia semakin menurun karena deforestasi selama ini. Data Statistik Kehutanan Tahun 2008 (Anonim, 2009) menunjukkan deforestasi hutan pada 7 pulau besar (Sumatra, Kalimantan, Sulawesi, Maluku, Papua, Jawa, Bali dan Nusa Tenggara) pada periode tahun 2000 sampai 2005 rata-rata sebesar 1,09 juta ha/tahun. Deforestasi dengan berbagai sebabnya merambah kawasan konsesi hingga hutan lindung. Kondisi ini menyebabkan berkurangnya pasokan kayu sebagai bahan baku industri kehutanan hingga potensi kepunahan terhadap jenis tertentu. Areal kosong akibat deforestasi perlu segera dipulihkan dengan penanaman sebagai upaya penghijauan danmendukung terwujudnya pembangunan hutan tanaman.

Permasalahan yang kini dihadapi adalah keunggulan mutu bibit, jumlah yang cukup dan tepat waktu untuk tujuan penanaman. Untuk mengatasi hal tersebut sudah seharusnya bibit tanaman yang dipilih memiliki kualitas unggul. Untuk mendapatkan kualitas bibit yang unggul perlu benih yang berasal dari sumber benih yang baik dan terpilih serta memenuhi kriteria sebagai sumber benih. Benih dicari dari pohon induk yang unggul karena dari asal benih yang baik diharapkan akan diperoleh keturunan yang baik pula.

Sorensen dan Campbel serta Schmidt dalam Suita (2009) menjelaskan bahwa ukuran benih berhubungan dengan viabilitas dan vigor benih, dimana benih dengan berat dan ukuran yang lebih besar memiliki kecepatan berkecambah dan perkembangan semai yang baik. Penelitian sebelumnya menggambarkan untuk jenis-jenis tertentu benih besar memiliki kualitas yang lebih baik daripada benih kecil. Suita (2009)melaporkan bahwa benih Melia azedarach L. yang berukuran besar menghasilkan bibit yang pertumbuhannya lebih cepat daripada benih kecil. Siregar (2010) juga melaporkan hal yang sama untuk benih jenis Gmelina arborea Linn. Namunpada jenis tertentu ukuran benih tidak berpengaruh signifikan.Chaisurisri et al. (1994) dalam Suita (2008)tidak menemukan hubungan yang nyata secara statistik antara benih berukuran besar dan kecil dengan pertumbuhan semai Picea sitchensis pada umur 8 bulan. Penelitian yang dilakukan Hendromono (1996) dalam Suita (2009) yang menyatakan bahwa benih Hymenaea courbaril yang berukuran besar menghasilkan bibit yang pertumbuhannya lebih cepat daripada benih kecil walaupun diameter pangkal batang bibit tersebut tidak berbeda nyata. Penelitian yang dilakukan Suita (2008) juga menunjukkan hasil yang sama, dimana pengaruh ukuran benih terhadap pertumbuhan diameter bibit 
Tanjung umur 3 bulan tidak menunjukkan perbedaan yang nyata.

S. leprosula merupakan jenis tanaman yang termasuk dalam famili Dipterocarpaceae dan famili ini tergolong paling banyak diperdagangkan. Peraturan Menteri Kehutanan No. P.11/MenhutII/2009 tentang Sistem Silvikultur, Sistem Silvikultur Tebang Pilih Tanam Jalur (TPTJ) memberikan gambaran bahwa dalam kegiatan TPTJ salah satu jenis tanaman yang digunakan adalah S. leprosula. Benih meranti tembaga (S. leprosula) mempunyai ukuran bervariasi kendatipun dalam pohon induk yang sama. Untuk jenis ini diduga benih berukuran besar memberikan keunggulan dalam hal pertumbuhan bibitnya. Penelitian ini bertujuan untuk mengetahui pengaruh ukuran benih terhadap laju pertumbuhan bibit S. leprosula. Dengan demikian upaya ini akan membantu meningkatkan penyediaan bibit bermutu untuk kegiatan penanaman.

\section{METODE PENELITIAN}

\section{A. Waktu dan Tempat}

Kegiatan penelitian dilaksanakan pada bulan Pebruari sampai September 2010 di persemaian Balai Besar Penelitian Dipterokarpa Samarinda.

\section{B. Bahan}

Bahan yaitu benih jenis $S$. leprosula, label benih, kantong plastik (polybag), plastik sungkup, top soil, pasir, kompos, sarlon, pupuk, fungisida dan insektisida. Benih berasal dari 6 pohon induk populasi hutan alam Gunung Bunga, Kalimantan Barat. Eksplorasi benih dilaksanakan bulan Pebruari 2010. Berdasarkan hasil survey pohon induk, saat eksplorasi buahnya telah masak secara fisiologis. Seleksi benih dilakukan manual yaitu dengan memilih benih yang bagus secara fisik.

\section{Metode Penelitian}

Penelitian ini menggunakan Rancangan Acak Lengkap dengan perlakuan ukuran benih, yaitu :

$\mathrm{B}_{1}=$ Ukuran benih kecil (panjang 0,7-0,99 $\mathrm{cm}$ dan diameter 0,63-0,80 cm)

$\mathrm{B}_{2}=$ Ukuran benih sedang (panjang 1-1.3 cm dan diameter 0,81-0,96 cm)

$\mathrm{B}_{3}=$ Ukuran benih besar (panjang 1.4-1,7 cm dan diameter 0,97-1,20 cm)

Setiap pohon induk terdiri dari tiga perlakuan, diulang tiga kali dan masing-masing ulangan terdiri dari 50 benih. Model umum penelitian ini adalah (Steel \& Torrie, 1995).

$\mathrm{Y}_{\mathrm{ij}}=\mu+\alpha_{\mathrm{i}}+\beta_{\mathrm{j}}+\varepsilon_{\mathrm{ij}}$, dimana:

$\mathrm{Y}_{\mathrm{ij}}=$ Respon variabel yang diukur pada ulangan ke $\mathrm{i}$, perlakuan kej

$\mu=$ Rata-rata(umum)

$\alpha_{\mathrm{i}}=$ Efek ulangan ke $\mathrm{i}$ 


$$
\begin{aligned}
& \beta_{\mathrm{j}}=\text { Efek perlakuan kej } \\
& \varepsilon_{\mathrm{ij}}=\text { Efek galat pada ulangan ke } \mathrm{i} \text {, perlakuan ke } \mathrm{j}
\end{aligned}
$$

Parameter yang diamati adalah daya kecambah benih (1), pertumbuhan tinggi dan diameter bibit (2). Untuk mengetahui parameter tersebut di atas digunakan persamaan:(Dirjen RRL, 1990).

$$
\begin{aligned}
& \text { Daya Kecambah }=\frac{\text { Jumlah benih yang berkecambah }}{\text { Jumlah benih yang dikecambahkan }} \times 100 \% \\
& P=q_{2}-q_{1}
\end{aligned}
$$

$$
\begin{array}{ll}
\text { dimana } & \mathrm{P} \\
& =\text { Pertumbuhan tanaman } \\
\mathrm{q}_{1} & =\text { Pengukuran awal } \\
\mathrm{q}_{2} & =\text { Pengukuran akhir }
\end{array}
$$

Data yang diperoleh kemudian dianalisis secara statistik menggunakan SPSS 16. Untuk mengetahui pengaruh perlakuan terhadap parameter yang diuji dianalisis dengan analisis varian.Apabila hasil ragam berbeda nyata dilakukan uji lanjutan dengan menggunakan Uji Tukey untuk menguji perbedaan rata-rata antar perlakuan.

\section{HASIL DAN PEMBAHASAN}

\section{A. Daya Kecambah}

Ukuran benih S. leprosula nampaknya mempengaruhi persen daya kecambah (Tabel 1). Analisis varian (Lampiran 1) menunjukkan bahwa ukuran benih berpengaruh sangat nyata terhadap daya kecambah benih. Hal ini sejalan dengan yang dikemukakan Schmidt (2002) bahwa proses perkecambahan dimulai dari proses imbibisi (penyerapan air), dimana laju penyerapan air ini sangat dipengaruhi oleh sifat fisiologi, biokimia dan morfologi dari benih terutama ukuran benih.

Tabel(Table) 1. Rata-rata daya kecambah benihS. leprosula (Average seed germination of S. leprosula)

\begin{tabular}{|c|c|c|c|c|}
\hline $\begin{array}{c}\text { Ukuran benih } \\
\text { (Seed size) }\end{array}$ & $\begin{array}{c}\text { Daya kecambah } \\
\text { (Germination) } \\
(\%)\end{array}$ & $\begin{array}{c}\text { Maksimal } \\
\text { (Maximum) }\end{array}$ & $\begin{array}{c}\text { Minimal } \\
\text { (Minimum) }\end{array}$ & $\begin{array}{c}\text { Std dev } \\
\text { (Std dev) }\end{array}$ \\
\hline $\mathrm{B}_{1}$ & $64,22^{\mathrm{a}}$ & 78 & 34 & 13,58 \\
$\mathrm{~B}_{2}$ & $77,00^{\mathrm{b}}$ & 96 & 54 & 11,65 \\
$\mathrm{~B}_{3}$ & $83,56^{\mathrm{b}}$ & 98 & 58 & 11,61 \\
\hline
\end{tabular}

Keterangan (Remarks): Angka yang diikuti huruf yang sama tidak berbeda nyata pada taraf 1\% (Values followed by same letters are not significantly different at $1 \%$ significant level) $\mathrm{B}_{1}$ : Ukuran benih kecil (Small seed size); $\mathrm{B}_{2}$ : Ukuran benih sedang (Medium-sized seed); $\mathrm{B}_{3}:$ Ukuran benih besar (Large seed size) 
Uji lanjut (Lampiran 2) memperlihatkan bahwa ukuran benih kecil berbeda nyatadengan ukuran benih besar, sedangkan ukuran benih sedang tidak berbeda nyata dengan ukuran benih besar.Benih yang berukuran besar cenderung berkecambah lebih cepat dan menghasilkan bibit yang lebih besar dan vigor daripada benih yang berukuran lebih kecil, karena ukuran embrio dan cadangan makanan yang lebih banyak (Schmidt, 2002).

Rata-rata daya kecambah benih menunjukkan kecenderungan semakin besar sejalan dengan semakin meningkatnya ukuran benih. Hal ini mungkin terjadi karena pengaruh ukuran benih. Benih yang memiliki ukuran besar berindikasi memiliki lebih banyak cadangan makanan dibanding dengan benih ukuran sedang dan kecil. Dengan cadangan makanan yang lebih banyak maka benih berukuran besar mempunyai daya kecambah dan kecepatan berkecambah yang lebih besar dan cepat dibanding dengan ukuran benih yang lebih kecil.

Dalam hubungannya dengan penyediaan bibit untuk kegiatan penanaman, makadaya kecambah ini menjadi penting. Informasi daya kecambah dengan ukuran benih tertentu dapat dijadikan pertimbangan awal mempersiapkan jumlah benih dalam kegiatan pembibitan di persemaian.

\section{B. Pertumbuhan Tinggi dan Diameter Bibit}

Tinggi dan diameter merupakan karakteristik pertumbuhan yang paling mudah diukur dan sering dijadikan standar dalam penentuan kualitas bibit. Ukuran benih S. leprosula memberikan hasil yang bervariasi terhadap rata-rata tinggi dan diameter bibit (Tabel 2). Analisis varian (Lampiran 3) menunjukkan bahwa ukuran benih berpengaruh nyata terhadap tinggi dan diameter bibit. Hasil uji lanjut memperlihatkan ukuran benih kecil, sedang dan besar berbeda nyata satu dengan lainnyabaik itu untuk tinggi maupun diameter bibit. Hasil ini sejalan dengan penelitian yang dilakukan Siregar (2010) yang menyatakan bahwa dari hasil uji beda Tukey, ukuran benih Gmelina(Gmelinaarborea Linn)memberikan pengaruh nyata terhadap tinggi bibit, diameter batang, panjang akar dan berat kering akan tetapi tidak berpengaruh nyata terhadap daya kecambah dan persen tumbuh bibit. Penelitian yang dilakukan Suita dan Megawati (2009) juga menunjukkan hasil yang sama, dimana pengaruh ukuran benih terhadap pertumbuhan tinggi dan diameter bibit Mindi (Melia azedarach L.) menunjukkan perbedaan yang nyata. 
Tabel (Table) 2. Rata-rata tinggi dan diameter bibit S. leprosula ( Average height and diameter of S. leprosula seed)

\begin{tabular}{|c|c|c|c|c|c|c|c|c|c|}
\hline \multirow[b]{2}{*}{$\begin{array}{c}\text { Ukuran } \\
\text { benih } \\
\text { (Seed } \\
\text { size) }\end{array}$} & \multicolumn{4}{|c|}{$\begin{array}{l}\text { Tinggi (Height) } \\
(\mathrm{cm})\end{array}$} & \multicolumn{5}{|c|}{$\begin{array}{l}\text { Diameter (Diameter) } \\
(\mathrm{cm})\end{array}$} \\
\hline & $\begin{array}{l}\text { Rata-rata } \\
\text { (Average) }\end{array}$ & $\begin{array}{l}\text { Maks } \\
(\text { Max })\end{array}$ & $\begin{array}{l}\text { Min } \\
(\text { Min })\end{array}$ & $\begin{array}{l}\text { Std } \\
\text { dev } \\
(\text { Std } \\
\text { dev })\end{array}$ & $\begin{array}{l}\text { Rata-rata } \\
\text { (Average) }\end{array}$ & $\begin{array}{l}\text { Maks } \\
(\text { Max })\end{array}$ & $\begin{array}{l}\text { Min } \\
(\text { Min })\end{array}$ & $\begin{array}{l}\text { Std } \\
\text { Dev } \\
(S t d \\
d e v)\end{array}$ & $\mathrm{N}$ \\
\hline $\mathrm{B}_{1}$ & $26,24^{\mathrm{a}}$ & 71 & 5 & 13,39 & $0,26^{\mathrm{a}}$ & 0,55 & 0,12 & 0,07 & 545 \\
\hline $\mathrm{B}_{2}$ & $29,13^{b}$ & 80 & 7 & 13,20 & $0,28^{\mathrm{b}}$ & 0,90 & 0,12 & 0,09 & 676 \\
\hline $\mathrm{B}_{3}$ & $34,18^{\mathrm{c}}$ & 81 & 7,5 & 15,85 & $0,31^{\mathrm{c}}$ & 1,05 & 0,14 & 0,10 & 730 \\
\hline
\end{tabular}

Keterangan (Remarks) : Angka yang diikuti huruf yang sama tidak berbeda nyata pada taraf 1\% (Values followed by same letters are not significantly different at $1 \%$ significant level)

$\mathrm{B}_{1}$ : Ukuran benih kecil (Small seed size); $\mathrm{B}_{2}$ : Ukuran benih sedang (Medium-sized seed) $; \mathrm{B}_{3}:$ Ukuran benih besar (Large seed size) $\mathrm{N}$ : Jumlah sampel (Population)

Data Tabel 2 memperlihatkan bahwa terdapat kecenderungan pertumbuhan tinggi dan diameter sejalan dengan semakin besarnya ukuran benih. Dengan demikian pengaruh ukuran benih terus berlanjut setelah perkecambahan. Benih yang memiliki ukuran besar akan semakin cepat berkecambah dan semakin cepat pula membentuk organ tanaman seperti akar, batang dan daun. Maka semakin cepat pula proses metabolisme dan fotosintesa yang kemudian memacu pertumbuhan tinggi dan diameter bibit.

\section{KESIMPULAN}

1. Benih S. leprosula ukuran besar (panjang 1,4-1,7 cm dan diameter 0,9-1,20 cm) menghasilkan daya kecambah, pertumbuhan tinggi dan diameter bibit lebih besar dibandingkan dengan benih yang berukuran kecil (panjang 0,7-0,99 $\mathrm{cm}$ dan diameter 0,63-0,80 cm).

2. Analisis secara statistik untuk parameter daya kecambah, benih besar berbeda nyata dengan biji kecil sedangkan antara benih sedang dan besar tidak berbeda nyata.Untuk tinggi dan diameter bibit menunjukkan perbedaan yang nyata baik ukuran benih kecil, sedang maupun besar.

\section{DAFTAR PUSTAKA}

Anonim. 2009. Statistik Kehutanan Indonesia 2008, Departemen Kehutanan

Direktorat Jenderal RRL.1990.Perlakuan pendahuluan benih cendana (Santalum album L.) dengan air $\left(\mathrm{H}_{2} \mathrm{O}\right)$, asam giberelin $\left(\mathrm{GA}_{3}\right)$ dan asam sulfat $\left(\mathrm{H}_{2} \mathrm{SO}_{4}\right)$. Bogor. 
Schmidt, L. 2002. Pedoman Penanganan Benih Tanaman Hutan Tropis dan Sub Tropis2000 (Versi Bahasa Indonesia). Direktorat Jenderal Rehabilitasi Lahan dan Perhutanan Sosial. Departemen Kehutanan. Jakarta

Siregar, N. 2010. Pengaruh Ukuran Benih Terhadap Perkecambahan Benih Dan Pertumbuhan Bibit Gmelina (Gmelina arborea Linn). Tekno Hutan Tanaman Vol 3 No 1 April.Pusat Penelitian dan Pengembangan Hutan Tanaman. Bogor

Steel,R.G.D \& J.H. Torrie. 1995. Prinsip dan Prosedur Statistik Suatu Pendekatan Biometrik. Penerbit PT Gramedia Pustaka Utama, Jakarta.

Suita, E. dan Nurhasybi. 2008. Pengaruh Ukuran Benih Terhadap Perkecambahan Dan Pertumbuhan Bibit Tanjung (Mimusops elengi L.). Jurnal Manajemen Hutan Tropika Vol XIV (2). Departemen Manajemen Hutan - Persatuan Sarjana Kehutanan Indonesia. Bogor

Suita, E. dan Megawati. 2009. Pengaruh Ukuran Benih Terhadap Perkecambahan Dan Pertumbuhan Bibit Mindi (Melia azedarach L.). Jurnal Penelitian Hutan Tanaman Vol 6 No 1 Pebruari. Pusat Penelitian dan Pengembangan Hutan Tanaman. Bogor 
Lampiran (Appendix) 1. Analisis sidik ragam pengaruh ukuran benih terhadap daya kecambah benih S. leprosula (Variance analysis on the effect of seed size to $\mathrm{S}$. leprosula seed germination)

\begin{tabular}{|c|c|c|c|c|c|}
\hline $\begin{array}{c}\text { Sumber Variasi } \\
\text { (Source of Variation) }\end{array}$ & $\begin{array}{c}\text { Jumlah Kuadrat } \\
\text { (Sum of Squares) }\end{array}$ & $\begin{array}{c}\text { Derajat Bebas } \\
\text { (Degree of Freedom) }\end{array}$ & $\begin{array}{c}\text { Kuadrat Rata-Rata } \\
\text { (Mean Square) }\end{array}$ & $\begin{array}{c}\text { F hitung } \\
\text { (F) }\end{array}$ & $\begin{array}{c}\text { Signifikan } \\
\text { (Sig.) }\end{array}$ \\
\hline $\begin{array}{c}\text { Perlakuan } \\
\text { (Treatments) }\end{array}$ & 3480.148 & 2 & 1740.074 & 11.475 & .000 \\
\hline & 7733.556 & 51 & 151.638 & & \\
\hline & 11213.704 & 53 & & & \\
\hline
\end{tabular}

Lampiran(Appendix) 2. Uji Tukey pengaruh ukuran benih terhadap daya kecambah benih S. leprosula (Turkey test on the effect of seed size to S. leprosula seed germination)

\begin{tabular}{|c|c|c|c|c|c|c|}
\hline \multirow{2}{*}{$\begin{array}{l}\text { (I) Ukuran } \\
\text { Benih } \\
\text { (Seed Size) }\end{array}$} & \multirow{2}{*}{$\begin{array}{l}\text { (J) Ukuran } \\
\text { Benih } \\
\text { (Seed Size) }\end{array}$} & \multirow{2}{*}{$\begin{array}{c}\text { Beda Rata-Rata } \\
\text { (Mean Difference) } \\
\text { (I-J) }\end{array}$} & \multirow{2}{*}{$\begin{array}{c}\text { Standar } \\
\text { Kesalahan } \\
\text { (Std. Error) }\end{array}$} & \multirow{2}{*}{$\begin{array}{l}\text { Signifikan } \\
\text { (Sig.) }\end{array}$} & \multicolumn{2}{|c|}{$\begin{array}{l}\text { 99\% Taraf Kepercayaan } \\
(99 \% \text { Confidence Interval) }\end{array}$} \\
\hline & & & & & $\begin{array}{c}\text { Batas Bawah } \\
\text { (Lower } \\
\text { Bound) }\end{array}$ & $\begin{array}{c}\text { Batas Atas } \\
\text { (Upper } \\
\text { Bound) }\end{array}$ \\
\hline \multirow{2}{*}{$\begin{array}{l}\text { Besar } \\
(\text { Large })\end{array}$} & $\begin{array}{c}\text { Sedang } \\
(\text { Medium })\end{array}$ & 6.556 & 4.105 & 256 & -5.96 & 19.07 \\
\hline & $\begin{array}{c}\text { Kecil } \\
(\text { Small })\end{array}$ & $19.333^{*}$ & 4.105 & 000 & 6.82 & 31.85 \\
\hline \multirow{2}{*}{$\begin{array}{l}\text { Sedang } \\
\text { (Medium) }\end{array}$} & $\begin{array}{l}\text { Besar } \\
\text { (Large) }\end{array}$ & -6.556 & 4.105 & 256 & -19.07 & 5.96 \\
\hline & $\begin{array}{c}\text { Kecil } \\
(\text { Small })\end{array}$ & $12.778^{*}$ & 4.105 & 008 & 26 & 25.29 \\
\hline \multirow{2}{*}{$\begin{array}{l}\text { Kecil } \\
(\text { Small })\end{array}$} & $\begin{array}{c}\text { Besar } \\
(\text { Large })\end{array}$ & $-19.333^{*}$ & 4.105 & 000 & -31.85 & -6.82 \\
\hline & $\begin{array}{c}\text { Sedang } \\
\text { (Medium) }\end{array}$ & $-12.778^{*}$ & 4.105 & 008 & -25.29 & -26 \\
\hline
\end{tabular}

*. The mean difference is significant at the 0.01 level

\section{Persen hidup (Percentage of Survival Seed)}

Tukey HSD

\begin{tabular}{|c|c|c|c|}
\hline \multirow{2}{*}{ Ukuran benih (Seed Size) } & \multirow{2}{*}{$\mathbf{N}$} & \multicolumn{2}{|c|}{ Subset for alpa $=\mathbf{0 . 0 1}$} \\
\cline { 3 - 4 } & & $\mathbf{1}$ & $\mathbf{2}$ \\
\hline Kecil (Small) & 18 & 64.22 & \\
\hline Sedang (Medium) & 18 & & 77.00 \\
\hline Besar (Large) & 18 & & 83.56 \\
\hline Signifikan (Sig.) & & 1.000 & 256 \\
\hline
\end{tabular}

Means for groups in homogeneous subsets are displayed. 
Lampiran (Appendix) 3. Analisis sidik ragam pengaruh ukuran benih terhadap rata-rata tinggi dan diameter bibit $S$. leprosula (Variance analysis on the effect of seed size to average height and seed diameter of $\mathrm{S}$. leprosula)

\begin{tabular}{|c|c|c|c|c|c|c|}
\hline & $\begin{array}{c}\text { Sumber Variasi } \\
\text { (Source of } \\
\text { Variation) }\end{array}$ & $\begin{array}{l}\text { Jumlah Kuadrat } \\
\text { (Sum of Squares) }\end{array}$ & $\begin{array}{c}\text { Derajat } \\
\text { Bebas } \\
\text { (Degree of } \\
\text { Freedom) }\end{array}$ & $\begin{array}{c}\text { Kuadrat } \\
\text { Tengah } \\
\text { (Mean Square) }\end{array}$ & $\underset{(F)}{\mathbf{F}}$ & $\begin{array}{c}\text { Signifikan } \\
\text { (Sig.) }\end{array}$ \\
\hline \multirow{3}{*}{$\begin{array}{l}\text { Tinggi bibit } \\
(\text { Height })\end{array}$} & $\begin{array}{c}\text { Perlakuan } \\
\text { (Treatment) }\end{array}$ & 20467.453 & 2 & 10233.726 & 45.793 & .000 \\
\hline & Galat (Error) & 435338.966 & 1948 & 223.480 & & \\
\hline & Jumlah (Total) & 455806.419 & 1950 & & & \\
\hline \multirow{3}{*}{$\begin{array}{l}\text { Diameter bibit } \\
\text { (Diameter) }\end{array}$} & $\begin{array}{c}\text { Perlakuan } \\
\text { (Treatment) }\end{array}$ & .592 & 2 & .206 & 38.351 & .000 \\
\hline & Galat (Error) & 15.044 & 1948 & .008 & & \\
\hline & Jumlah (Total) & 15.637 & 1950 & & & \\
\hline
\end{tabular}

Lampiran (Appendix) 4. Uji Tukey pengaruh ukuran benih terhadap rata-rata tinggi dan diameter bibit S. leprosula (Tukey test on the effect of seed size to average height and diameter of S. leprosula)

\begin{tabular}{|c|c|c|c|c|c|c|c|}
\hline \multirow{2}{*}{\begin{tabular}{|l|}
\multicolumn{1}{|l}{ Variabel } \\
Tergantung \\
(Dependent \\
Variable)
\end{tabular}} & \multirow{2}{*}{$\begin{array}{l}\text { (I) Ukuran } \\
\text { Benih } \\
\text { (Seed Size) }\end{array}$} & \multirow{2}{*}{$\begin{array}{l}\text { (J) Ukuran } \\
\text { Benih } \\
\text { (Seed Size) }\end{array}$} & \multirow{2}{*}{$\begin{array}{c}\text { Beda Rata-Rata } \\
\text { (Mean } \\
\text { Difference) } \\
\text { (I-J) }\end{array}$} & \multirow{2}{*}{$\begin{array}{c}\text { Standar } \\
\text { kesalahan } \\
\text { (Std. } \\
\text { Error) }\end{array}$} & \multirow{2}{*}{$\begin{array}{c}\text { Signifikan } \\
\text { (Sig.) }\end{array}$} & \multicolumn{2}{|c|}{$\begin{array}{l}\text { 99\% Taraf Kepercayaan } \\
\text { (99\% Confidence Interval) }\end{array}$} \\
\hline & & & & & & $\begin{array}{c}\text { Batas Bawah } \\
\text { Lower } \\
\text { Bound })\end{array}$ & $\begin{array}{l}\text { Batas Atas } \\
\text { (Upper } \\
\text { Bound }\end{array}$ \\
\hline \multirow{6}{*}{$\begin{array}{l}\text { Tinggi bibit } \\
(\text { Height })\end{array}$} & \multirow{2}{*}{$\begin{array}{l}\text { Besar } \\
\text { (Large) }\end{array}$} & $\begin{array}{l}\text { Sedang } \\
\text { (Medium) }\end{array}$ & $4.74971^{*}$ & .79795 & .000 & 2.4221 & 7.0773 \\
\hline & & $\begin{array}{l}\text { Kecil } \\
(\text { Small })\end{array}$ & $7.93626^{*}$ & .84628 & .000 & 5.4677 & 10.4048 \\
\hline & \multirow{2}{*}{$\begin{array}{l}\text { Sedang } \\
\text { (Medium) }\end{array}$} & $\begin{array}{l}\text { Besar } \\
\text { (Large) }\end{array}$ & $-4.74971^{*}$ & .79795 & .000 & -7.0773 & -2.4221 \\
\hline & & $\begin{array}{l}\text { Kecil } \\
(\text { Small })\end{array}$ & $3.18655^{*}$ & .86061 & .001 & 6762 & 5.6969 \\
\hline & \multirow{2}{*}{$\begin{array}{l}\text { Kecil } \\
(\text { Small })\end{array}$} & $\begin{array}{l}\text { Besar } \\
\text { (Large) }\end{array}$ & $-7.93626^{*}$ & .84628 & .000 & -10.4048 & -5.4677 \\
\hline & & $\begin{array}{l}\text { Sedang } \\
\text { (Medium) }\end{array}$ & $-3.18655^{*}$ & .86061 & .001 & -5.6969 & -6762 \\
\hline \multirow{6}{*}{$\begin{array}{c}\text { Diameter bibit } \\
\text { (Diameter) }\end{array}$} & \multirow{2}{*}{$\begin{array}{l}\text { Besar } \\
\text { (Large) }\end{array}$} & $\begin{array}{c}\text { Sedang } \\
(\text { Medium })\end{array}$ & $.02700^{*}$ & .00469 & .000 & .0133 & .0407 \\
\hline & & $\begin{array}{l}\text { Kecil } \\
(\text { Small })\end{array}$ & $.04225^{*}$ & .00467 & .000 & .0277 & .0568 \\
\hline & \multirow{2}{*}{$\begin{array}{l}\text { Sedang } \\
\text { (Medium) }\end{array}$} & $\begin{array}{l}\text { Besar } \\
\text { (Large) }\end{array}$ & $-.02700^{*}$ & .00469 & .000 & -.0407 & -.0133 \\
\hline & & $\begin{array}{c}\text { Kecil } \\
(\text { Small })\end{array}$ & $.01525^{*}$ & .00506 & .007 & .0005 & .0300 \\
\hline & \multirow{2}{*}{$\begin{array}{l}\text { Kecil } \\
(\text { Small })\end{array}$} & $\begin{array}{l}\text { Besar } \\
\text { (Large) }\end{array}$ & $-.04225^{*}$ & .00497 & .000 & -.0568 & -.0277 \\
\hline & & $\begin{array}{c}\text { Sedang } \\
\text { (Medium) }\end{array}$ & $-.01525^{*}$ & .00506 & .007 & -.0300 & -.0005 \\
\hline
\end{tabular}

*. The means difference is significant at the 0.01 level 


\section{Tinggi bibit (Seed height)}

Tukey HSD

\begin{tabular}{|c|c|c|c|c|}
\hline \multirow{2}{*}{$\begin{array}{c}\text { Ukuran benih } \\
\text { (Seed Size) }\end{array}$} & \multirow{2}{*}{$\mathrm{N}$} & \multicolumn{3}{|c|}{ Subset for alpha $=0.01$} \\
\cline { 3 - 5 } & & 1 & 2 & 3 \\
\hline Kecil (Small) & 545 & 26.2396 & & \\
Sedang (Medium) & 676 & & 29.4262 & \\
Besar (Large) & 730 & & & 34.1759 \\
\hline Signifikan (Sig.) & & 1.000 & 1.000 & 1.000 \\
\hline
\end{tabular}

Means for groups in homogeneous subsets are displayed.

\section{Diameter bibit (Seed diameter)}

Tukey HSD

\begin{tabular}{|c|c|c|c|c|}
\hline \multirow{2}{*}{$\begin{array}{c}\text { Ukuran benih } \\
\text { (Seed Size) }\end{array}$} & \multirow{2}{*}{$\mathrm{N}$} & \multicolumn{3}{|c|}{ Subset for alpha =0.01 } \\
\cline { 3 - 5 } & & 1 & 2 & 3 \\
\hline Kecil (Small) & 545 & .2641 & & \\
Sedang (Medium) & 676 & & .2794 & .3064 \\
Besar (Large) & 730 & & & 1.000 \\
\hline Signifikan (Sig.) & & 1.000 & 1.000 & \\
\hline
\end{tabular}

Means for groups in homogeneous subsets are displayed. 